\section{EDUCACIÓN PATRIMONIAL Y TIC EN ESPAÑA: MARCO NORMATIVO, VARIABLES ESTRUCTURANTES $Y$ PROGRAMAS REFERENTES}

\author{
Alex Ibáñez-Etxeberria \\ Universidad del País Vasco \\ ORCID iD: https://orcid.org/0000-0001-9495-5155 \\ alex.ibanez@ehu.eus \\ Olaia Fontal Merillas \\ Universidad de Valladolid \\ ORCID iD: https://orcid.org/0000-0003-1216-3475 \\ ofontal@mpc.uva.es \\ Pilar Rivero Gracia \\ Universidad de Zaragoza \\ ORCID iD: https://orcid.org/0000-0002-6757-7598 \\ privero@unizar.es
}

\begin{abstract}
Cómo citar este artículo/Citation: Ibáñez-Etxeberria, A., Fontal Merillas, O. y Rivero Gracia, P. (2018). Educación patrimonial y TIC en España: marco normativo, variables estructurantes y programas referentes. Arbor, 194 (788): a448. https://doi. org/10.3989/arbor.2018.788n2008
\end{abstract}

Recibido: 6 marzo 2015. Aceptado: 8 febrero 2016

RESUMEN: El presente trabajo realiza un análisis de la situación de la educación patrimonial basada en las tecnologías de la información y comunicación (TIC) en España, presentando una síntesis de la legislación referente a la enseñanza del patrimonio para, posteriormente y a partir de la labor de revisión, caracterización y puesta en valor realizada por el Observatorio de Educación Patrimonial en España, definir una relación de variables estructurantes y presentar una selección de casos significativa de las tendencias actuales de cara a definir las perspectivas de futuro de la aplicación de las TIC para educación patrimonial en España.

PALABRAS CLAVE: Educación patrimonial; evaluación de programas; tecnologías de la información y comunicación; legislación educativa.

\section{HERITAGE EDUCATION AND ICT IN SPAIN: REGULATORY FRAMEWORK, STRUCTURING VARIABLES AND MAIN POINTS OF REFERENCE}

Copyright: (C) 2018 CSIC. Este es un artículo de acceso abierto distribuido bajo los términos de la licencia de uso y distribución Creative Commons Reconocimiento 4.0 Internacional (CC BY 4.0).

ABSTRACT: The present work analyzes the situation of Heritage Education based on information and communications technology (ICT) in Spain, synthesizing the legislation on heritage education in this country. We propose some structuring variables and a selection of representative programmes based on the review, definition and valuation through research of the Spanish Heritage Education Observatory in order to define the perspectives for the future related to the application of the ICT in Heritage Education in Spain.

KEYWORDS: Heritage education; Evaluation of programs; Information and communications technology; educative legislation. 


\section{INTRODUCCIÓN: MARCO NORMATIVO}

\section{De la LOGSE a la LOMCE: El patrimonio como materia curricular en España y su práctica educativa}

El patrimonio lleva veinticinco años presente de manera explícita en el currículo educativo español desde que con la LOGSE$^{1}$ (1990-2006) se incluyera entre los objetivos generales de Educación Primaria "conocer el patrimonio cultural, participar en su conservación y mejora y respetar la actitud de interés y respeto hacia el ejercicio de este derecho", vinculando su desarrollo a las áreas de Conocimiento del medio natural, social y cultural y Educación artística. La primera de ellas situaba entre sus objetivos "analizar algunas manifestaciones de la intervención humana en el medio, valorar críticamente la necesidad y el alcance de las mismas y adoptar un comportamiento en la vida cotidiana acorde con la postura de defensa y recuperación del equilibrio ecológico y de conservación del patrimonio cultural". Por su parte, en Educación Secundaria Obligatoria, el patrimonio se aproximaba a la dimensión actitudinal, encontrándose entre los objetivos generales de etapa "conocer, respetar y valorar las creencias, actitudes y valores de nuestro acervo cultural y patrimonio histórico-artístico" y "conocer y apreciar el patrimonio cultural y lingüístico de España, atendiendo a su diversidad pluricultural y plurilingüe".

La $\operatorname{LOE}^{2}$ (2006-2014), sin explicitar una definición de patrimonio, desvelaba un enfoque completo en cuanto a sus ámbitos (cultural, artístico, histórico, musical, danza, artes plásticas, arte de nuestro tiempo, manifestaciones culturales específicas de la motricidad humana tales como los deportes, los juegos tradicionales, las actividades expresivas...) y complejo en cuanto a su naturaleza (material e inmaterial). Además, se resaltaba su dimensión humana, individual o colectiva, entendida como parte consustancial al propio concepto de patrimonio, situando el acento en la propiedad o la pertenencia, y acorde a las tendencias internacionales, aproximando su tratamiento a un enfoque identitario. Entre las ocho competencias básicas que estructuraban el currículum, el patrimonio constituía un referente fundamental para el desarrollo de la Competencia cultural y artística.

En la LOMCE ${ }^{3}$, se mantiene la fuerte presencia del patrimonio en la etapa de Primaria, apareciendo entre los objetivos generales la necesidad de "conocer, comprender y respetar las diferentes culturas", siendo principalmente el área de Ciencias sociales la que se ocupa del mismo, orientando a que "el alumnado desarrolle la curiosidad por conocer las formas de vida humana en el pasado y que valore la importancia que tienen los restos para el conocimiento y estudio de la historia y como patrimonio cultural que hay que cuidar y legar", y buscando la capacidad para "valorar y respetar el patrimonio natural, histórico, cultural y artístico, y asumir las responsabilidades que supone su conservación y mejora", aspectos incluidos como criterios de evaluación. Una novedad en el diseño curricular es la incorporación de una serie de estándares de aprendizaje que concretan cada criterio de evaluación hasta el punto de constituir en la práctica una serie de actividades obligatorias. Asociados a los criterios mencionados se hallan los siguientes estándares:

\footnotetext{
"identifica, valora y respeta el patrimonio natural, histórico, cultural y artístico y asume las responsabilidades que supone su conservación y mejora; respeta los restos históricos y los valora como un patrimonio que debemos legar y reconoce el valor que el patrimonio arqueológico monumental nos aporta para el conocimiento del pasado; respeta y asume el comportamiento que debe cumplirse cuando visita un museo o un edificio antiguo; y aprecia la herencia cultural a escala local, nacional y europea como riqueza compartida que hay que conocer, preservar y cuidar".
}

Así, podemos concluir que la LOMCE insiste en la dimensión histórica, y vuelve a incidir en acciones como el conocimiento, el estudio, la valoración, el respeto y la responsabilización ciudadana en el devenir del legado histórico y cultural desde la Educación Primaria, aunque cabría preguntarse si realmente desarrolla los contenidos históricos necesarios para dotar de herramientas al alumnado que le permitan comprender realmente el patrimonio (Pelegrín Campo, 2015). En Educación Secundaria, encontramos un despliegue de actuaciones en relación con el patrimonio, abordando contenidos explícitos relacionados con el patrimonio artístico, cultural, histórico, geológico, natural, literario, artístico y musical, así como la inclusión de contenidos de historia del arte en la asignatura de Historia Contemporánea de primero de Bachillerato.

Si la lectura del marco normativo demuestra que el patrimonio ha tenido y tiene una presencia considerable en los textos curriculares en España que las concreciones autonómicas han desarrollado aún más (Fontal Merillas, 2016), el análisis de la práctica docente en España refleja un uso reducido. Así se desprende del estudio Análisis del tratamiento del Patrimonio Cultural en la legislación educativa vigente que, tras recoger que el $69,7 \%$ de los centros participantes en el estudio ( $n=682$ ) declaraban que se podría mejorar la presencia del patrimonio en el currículum, desvelaba 
que, frente al $80,8 \%$ de docentes que declaraban trabajar el patrimonio en su centro, tan solo el $18 \%$ había llevado a cabo algún proyecto, programa o actividad específica de innovación educativa en relación con el patrimonio cultural (Fontal, 2013). En la misma línea, estudios centrados en el análisis del tratamiento del patrimonio en los libros de texto indican que es usado frecuentemente como ilustración y recurso educativo, destacándose los elementos histórico-artísticos sobre otras manifestaciones patrimoniales pero predominando la consideración de los valores estilísticos y monumentales (Cuenca y López, 2014).

Estos datos, puestos en relación con el análisis de la presencia del patrimonio en el currículum, pueden estar indicando que es frecuente que se sitúe la excusa o problema en las leyes educativas, cuando la normativa no solo es suficiente sino además completa en cuanto a los contenidos patrimoniales.

\section{La gestión educativa del patrimonio desde la adminis- tración: el Plan Nacional de Educación y Patrimonio}

El Plan Nacional de Educación y Patrimonio (PNEyP) forma parte de los Planes Nacionales de Patrimonio Cultural, creados como instrumentos de gestión de los bienes culturales, y cuya coordinación se realiza desde el Instituto del Patrimonio Cultural en España (IPCE) del Ministerio de Cultura. En 2013 se aprobó el PNEyP, que cuenta con dos programas generales, el de Investigación en educación patrimonial e innovación en didáctica del Patrimonio, y el de Formación de educadores, gestores y otros agentes culturales $e$ investigadores en educación patrimonial (Fontal Merillas e Ibáñez Etxeberria, 2015).

Los objetivos del PNEyP se centran en definir las bases teóricas y criterios de la educación patrimonial, fomentar la investigación e incorporarla como línea de desarrollo prioritario en el marco de los planes estratégicos de las administraciones; también pretende garantizar la implementación de la normativa educativa, al objeto de favorecer la inserción curricular de contenidos patrimoniales, su preservación, valoración y disfrute público, crear instrumentos de coordinación que garanticen la colaboración entre educadores y gestores, fomentar la elaboración de materiales educativos, integrar las líneas de actuación orientadas a la didáctica de los bienes patrimoniales en las herramientas de gestión del patrimonio cultural, difundir programas y acciones educativas y promocionar la cooperación española en programas y acciones internacionales (Domingo, Fontal, Cirujano y Ballesteros, 2013, pp. 7-8).
La importancia de las TIC en el Plan Nacional de Educación y Patrimonio

El PNEyP, tiene muy en cuenta la dimensión tecnológica de la educación y, dentro del programa dedicado a la investigación, se señala como línea prioritaria "la integración de las TIC en nuevos modelos de enseñanza-aprendizaje" (Domingo et al., 2013, p. 18), recogiendo un concepto abierto de TIC y reconociendo la variada naturaleza de sus manifestaciones y las posibilidades educativas que pueden derivarse de su uso en el trabajo con el patrimonio. Esta incorporación en los nuevos modelos de educación patrimonial se plantea como medio y no como un fin en sí misma. Se trata, en definitiva, de la aplicación de todas las posibilidades que brindan los entornos 2.0 y 3.0 al ámbito de la educación patrimonial, generando un escenario que permita una educación complementaria a la educación presencial, promoviendo la construcción de nuevos modos de organizar y acceder a la información y a los conocimientos.

Sobre la base de estas cuestiones, el PNEyP define unos criterios o estándares de calidad deseables en las propuestas de educación patrimonial con uso de TIC, que se concretan en: claridad de ideas, programas y contenidos, así como herramientas y soportes de facilidad de uso (usabilidad) y funcionalidad (funcionabilidad) que permitan garantizar el valor efectivo y la buena aplicabilidad de estos nuevos modelos de enseñanza-aprendizaje; definición de recursos y actividades encaminados a distintos grupos, en función de edades y competencias; consideración de la heterogeneidad de los grupos presentes en las redes sociales educativas, favoreciendo un intercambio intergeneracional, interregional y multicultural en la construcción del conocimiento; dotación técnica y estímulo de su uso a los agentes implicados para favorecer su integración pedagógica; diseño de programas para la formación del profesorado y otros agentes, para que puedan estudiar a fondo las características y potencialidades de los nuevos recursos y crear contenidos que se ajusten a sus objetivos, así como la creación de narrativas integradas en el discurso que capten la atención del usuario.

Considerando lo anterior y siempre en el ámbito de las TIC, el PNEyP establece cinco líneas de actuación específicas: formación orientada a los agentes patrimoniales, dotación de infraestructuras, desarrollo de software, análisis del impacto de las TIC en la educación y diseño de un portal web. Además, dentro del programa de investigación e innovación se define una actuación específica orientada al análisis del impac- 
to de los medios de comunicación, redes sociales y otros medios virtuales en la formación patrimonial de la sociedad. En definitiva, se pretende profundizar en las posibilidades de localización, intercambio, debate y difusión que permiten las tecnologías de la información y comunicación. (Domingo et al., 2013, pp. 19-21). Ya en el segundo programa, dedicado a la formación, se hacen varias referencias a la formación en TIC, entendidas como recursos didácticos y medios de enseñanza-aprendizaje, para lo que se insiste en la necesidad de adquirir competencias que permitan aprovechar las potencialidades de estas tecnologías, sus puntos fuertes y débiles, un conocimiento logístico, el diseño de estrategias de enseñanza-aprendizaje, la búsqueda de un empleo efectivo de las TIC, etc. (Domingo et al., 2013, p. 30).

Por tanto, el PNEyP -que pretende incidir en las políticas educativas del ámbito formal, pero también no formal e informal-, ha situado las TIC como medios, contextos, contenidos y recursos para la educación patrimonial, lo que confiere a este plan un carácter actualizado y completo en la concepción de la relación entre patrimonio y TIC.

\section{ESTUDIO: ANÁLISIS Y EVALUACIÓN DE PROGRAMAS EDUCATIVOS QUE ABORDAN EL PATRIMONIO ME- DIANTE EL USO DE LAS TIC}

Tomando como punto de partida la legislación educativa y las herramientas administrativas al servicio del desarrollo de la educación patrimonial, proponemos un estudio que, partiendo del inventario y análisis de programas que se plantean el uso de TIC, determine mediante una evaluación basada en estándares, algunos ejemplos de buenas prácticas que sirvan para ayudar a definir enfoques y modelos adecuados en el uso de TIC en educación patrimonial. Para ello, utilizaremos como base los instrumentos que nos ofrece el Observatorio de Educación Patrimonial en España (OEPE), vinculado al PNEyP.

\section{Panorama de la educación patrimonial en España: OEPE}

El OEPE, nace con el objetivo de localizar, inventariar, analizar y evaluar los programas de educación patrimonial generados en España. Creado y desarrollado a partir de dos proyectos de I+D+i, ha generado una base de datos que contiene 1.700 entradas referenciadas, que inventaría hasta dieciséis tipologías educativas de programas de educación patrimonial (véase tabla 1).

OEPE, integrado además dentro del PNEyP, cumple la función de investigación continua y seguimiento de
Tabla 1. Categorización y codificación de tipologías educativas de programas de educación patrimonial en el OEPE

\begin{tabular}{|l|l|}
\hline PGE: Programa educativo & PI:Proyecto de investigación \\
\hline PYE: Proyecto educativo & PM: Proyecto de mejora \\
\hline DE: Diseño didáctico & C: Concurso \\
\hline RD: Recurso didáctico & R: Ruta \\
\hline H: Herramienta & P: Plan \\
\hline AE: Acción educativa & R: Red \\
\hline AA: Actividad aislada & EC: Evento científico \\
\hline T: Taller & EF: Evento formativo \\
\hline
\end{tabular}

Fuente: elaboración propia.

las acciones y líneas proyectuales desarrolladas en la materia de educación patrimonial (Domingo et al., 2013, p. 7). Dentro del programa de investigación en educación patrimonial e innovación en didáctica del Patrimonio, se define como línea específica la observación permanente de la educación patrimonial en España, en la que se espera del OEPE que aborde el seguimiento de cuantas iniciativas o líneas proyectuales sean desarrolladas en la materia objeto de su competencia, tanto en España como en el marco de la Unión Europea. Por ello el observatorio recoge también toda la información relativa a las actividades, programas, proyectos, planes, redes, jornadas, cursos, concursos, etc. que se lleven a cabo en España y, al mismo tiempo, sirve como herramienta de difusión de los programas más significativos, actuando como punto de encuentro para quienes deseen profundizar en la educación patrimonial (Domingo et al., 2013, p.19).

\section{Instrumentos y recogida de datos}

Los datos y evidencias referentes a programas y acciones de educación patrimonial se recogen desde el OEPE en dos fases, una primera de inventario de acciones $y$ programas, describiendo sus características y, una segunda, donde se seleccionan aquellos que reúnen los estándares de calidad generales y específicos de cada tipología educativa. Así, OEPE emplea un sistema de filtros secuenciado, que parte de la búsqueda y localización de programas y acciones conforme a una serie de indicadores definidos por un equipo de expertos, que conforma una muestra amplia (véase tabla 2). Sobre esa relación de programas localizados, se aplica un segundo filtro en base a 23 criterios de inclusión y 14 de exclusión, que determinan en el tercer paso su inventario final en la base de datos. El cuarto paso es efectuar análisis estadístico-descriptivos, centrados fundamentalmente en 
conocer las tipologías patrimoniales y educativas, la geolocalización de los programas, el grado de concreción del diseño, el tipo de implementación o instrumentos que emplean, etc.; un tipo de análisis que resulta útil para detectar tendencias, ausencias y necesidades.

En el quinto paso, se seleccionan aquellos programas que se aproximan a los estándares generales de calidad ya definidos, vinculados al diseño, la implementación y los resultados. De entre ellos, los que obtienen un mayor nivel de adecuación a los estándares son seleccionados para realizar en el sexto paso una evaluación extendida, donde se incluye además una evaluación específica relacionada con su tipología educativa. Finalmente, aquellos programas que destacan por su excelencia son seleccionados para realizar estudios de caso, individuales o sectoriales, según proceda. Este, a su vez, redefine los criterios de búsqueda iniciales, en una secuencia circular, de manera que se va tendiendo a la localización de programas más próximos a una educación patrimonial de calidad. De este modo, cerramos un círculo que nos permite definir un sistema de filtros basado en criterios de inclusión/excusión, análisis estadístico descriptivo, evaluación basada en estándares básica, evaluación basada en estándares extendida y estudio de casos (véase figura 1) (Fontal, 2016).

\section{Ficha de inventario OEPE}

Elemento clave del paso 3, acceder a la misma supone entrar de hecho en la base de datos OEPE, obteniendo el reconocimiento de acción de educación patrimonial desde el PNEyP. Esta ficha se organiza en cinco bloques dedicados a la identificación y localización, la descripción, los datos del diseño educativo, su relación con otras fichas y finalmente, si fuera el caso, un anexo documental. En conjunto, la ficha de inventario se compone de 42 campos más el anexo documental, que permite incluir documentos escritos, audiovisuales y enlaces (links).

\section{Tablas de estándares básica y extendida y anexo tecnológico}

En los pasos 5 y 6, encontramos la evaluación basada en estándares generales y específicos de cada una de las dieciséis tipologías educativas ya mencionadas (véase tabla 1 ). Los programas son analizados en aspectos referidos a su diseño, implementación y resultados. Además, tras la definición de estándares generales y específicos por cada tipología educativa, se efectúa una selección de programas para realizar un análisis de conteni-

Figura 1. Sistema de filtros: procedimiento secuencial de selección de programas desde el inventario hasta el estudio de casos.

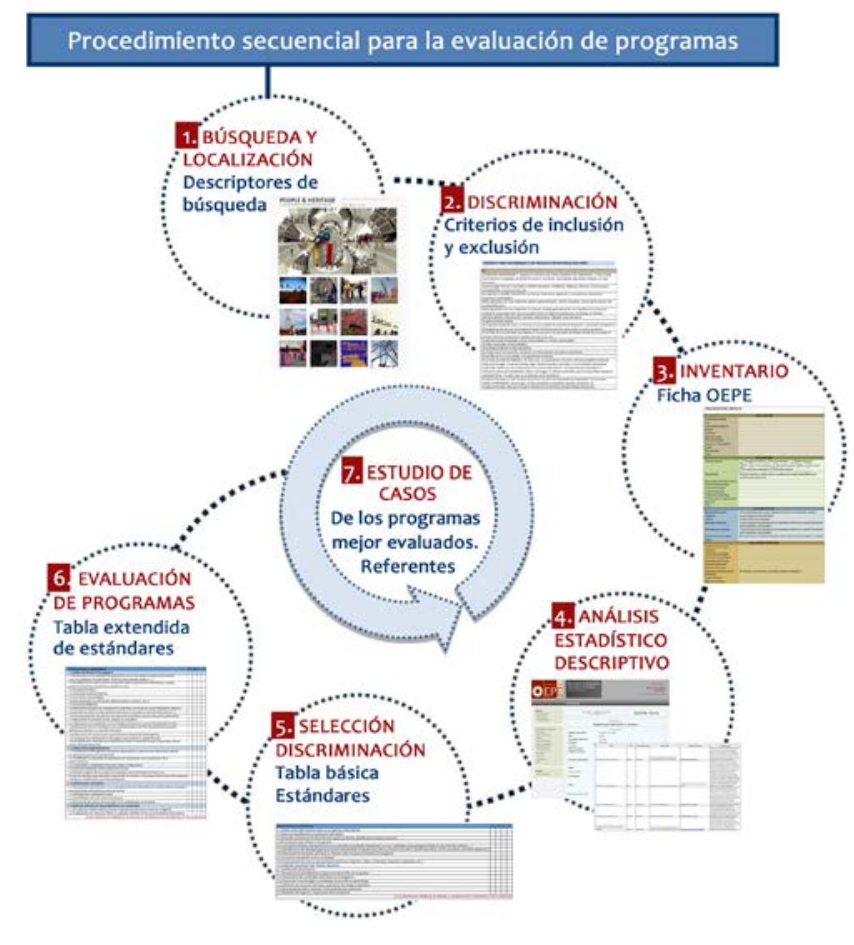

Fuente: elaboración propia. 
do y, tras una selección de programas referentes, una evaluación basada en estándares, centrada en analizar el enfoque/modelo teórico, los objetivos, la estructura de los diseños, la planificación de las actuaciones, el grado de cumplimiento y adecuación de la planificación (implementación), así como la calidad de los resultados e impactos generados (de Miguel, 2000, p. 294).

Los estándares básicos han sido definidos partiendo de los tres primeros análisis estadísticos en los que se analizaban 350, 644 y 1.120 programas respectivamente, e incluyendo los criterios derivados del PNEyP, que se refieren a la calidad de la información sobre el programa y al grado de concreción del diseño (véase tabla 2). Esta herramienta cuantifica el grado de acercamiento al nivel óptimo de cumplimento del estándar de calidad, de manera que posteriormente se puedan unificar los informes. Para ello, se concretan en rúbricas que permiten identificar los criterios de evaluación para cada grado, en este caso cualitativo, donde A equivale a se alcanza con calidad, B a se alcanza, C a se alcanza con condiciones y $\mathrm{D}$ a no se alcanza.

Este mismo sistema es el que permite la creación de la submuestra a la que se aplica, dentro del paso 6, la tabla de estándares extendidos, más específicos y detallados, y en la que además, relevante para este trabajo, se aplica un anexo de estándares específicos relacionados con la dimensión tecnológica para propuestas que impliquen el uso de TIC (véase tabla 3).

A partir de ese momento, comienza el estudio de cada caso sectorial propiamente dicho, entre ellos, aquel al que se refiere este trabajo, para el cual ha- remos una selección de programas que, habiendo cumplido los estándares de calidad extendidos, hayan presentado resultados de manera pública, convirtiéndose en nuestros programas referentes.

\section{ANÁLISIS DE DATOS Y RESULTADOS: VARIABLES ESTRUCTURANTES Y PROGRAMAS REFERENTES}

\section{Descripción de la muestra}

La base de datos OEPE contiene 1.406 programas inventariados ${ }^{4}$ de los cuales, independientemente de su tipología educativa, 56 contienen el descriptor TIC, lo que viene a suponer el 3,98\% del total (véase tabla 4).

De los 56 programas clasificados como tecnológicos, $20(35,7 \%)$ se incluyen en la categoría patrimonio inmaterial, $34(60,7 \%)$ se localizan en la categoría patrimonio cultural, y en menor medida aparecen combinadas las categorías de monumentos: obra arquitectónica (5), patrimonio natural y cultural (4), monumentos: arqueología (3) o tan solo 1 programa en las categorías monumentos: obra escultórica; monumentos: inscripción en cavernas; monumentos: obra pictórica; lugares arqueológicos y por último en la categoría lugares: creados por el hombre.

Si nos centramos en las tipologías educativas a las que atienden, quince son recursos didácticos $(26,7 \%)$, once son proyectos educativos $(19,6 \%)$, seis son proyectos de investigación (10,7\%), cinco herramientas didácticas, cuatro acciones educativas, cuatro programas educativos, cuatro rutas o itinerarios didácticos, dos son redes y, dentro de las tipologías proyecto de mejora, diseño didáctico, actividad aislada, curso y taller encontramos un programa en cada una de ellas.

Tabla 2. Estándares básicos

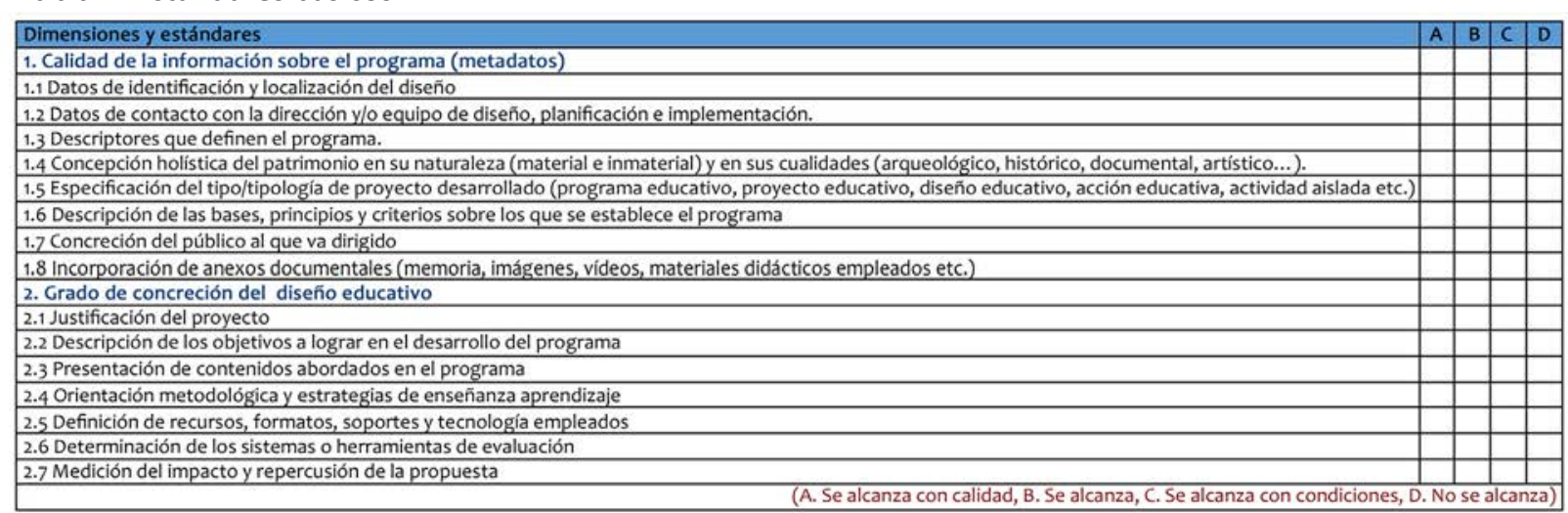

Fuente: elaboración propia. 
Tabla 3. Tabla de estándares extendida y anexo con criterios específicos para la dimensión tecnológica.

\begin{tabular}{|c|c|c|c|c|}
\hline Dimensiones y estándares & A & B & C & D \\
\hline 1. Calidad del diseño del programa & & & & \\
\hline $\begin{array}{l}\text { 1.1 Diversidad en la concepción del patrimonio: en su naturaleza (material e inmaterial) } \\
\text { y en sus cualidades (arqueológico, histórico, documental, artístico...). }\end{array}$ & & & & \\
\hline $\begin{array}{l}\text { 1.2 Pluralidad de los valores que se proyectan sobre el patrimonio: identitarios, sociales, } \\
\text { políticos, históricos, económicos, emotivos, etc.). }\end{array}$ & & & & \\
\hline 1.3 Consistencia teórica & & & & \\
\hline 1.4 Coherencia teórico-empírica & & & & \\
\hline 1.5 Concreción metodológica & & & & \\
\hline 1.6 Estructuración y secuenciación didáctica (fases, acciones, etc.) & & & & \\
\hline 1.7 Innovación didáctica & & & & \\
\hline 1.8 Adecuación al grado de competencia congnitiva, curricular y/o social del público objetivo & & & & \\
\hline 1.9 Inclusión de varias escalas patrimoniales (local, autonómica, estatal, internacional...) & & & & \\
\hline 1.10 Incorporación de mecanismos de evaluación especíicos para la educación patrimonial & & & & \\
\hline 1.11 Adecuación al contexto social, cultural y/o educativo & & & & \\
\hline 1.12 Adecuación a lo estipulado en el currículum nacional y/o autonómico (ámbito fomal) & & & & \\
\hline $\begin{array}{l}\text { 1.13 Adecuación de los contenidos a los estandarizados en el Plan Nacional de Educación } \\
\text { Patrimonial (ámbitos no formal e informal) }\end{array}$ & & & & \\
\hline 1.14 Adecuación de los recursos y soportes para el desarrollo del programa & & & & \\
\hline 1.15 Composición multidisciplinar del equipo para el diseño y la planificación & & & & \\
\hline $\begin{array}{l}\text { 1.16 Sensibilización: Abordan la sensibilización desde la cadena conocer-comprender-valorar- } \\
\text { cuidar- disfrutar-transmitir }\end{array}$ & & & & \\
\hline 2. Calidad de la implementación & & & & \\
\hline $\begin{array}{l}2.1 \text { Coordinación entre agentes educativos (educadores y gestores del Patrimonio Cultural } \\
\text { en materia de educación patrimonial) }\end{array}$ & & & & \\
\hline $\begin{array}{l}\text { 2.2 Flexibilidad: La capacidad de adaptación de lo diseñado a las condiciones de la } \\
\text { implementación }\end{array}$ & & & & \\
\hline 2.3 Continuidad y estabilidad temporal (medio y largo plazo) & & & & \\
\hline 2.4 Internacionalización de las implementaciones & & & & \\
\hline 2.5 Revisión y ajuste de los propios procesos por parte del implementador, etc. & & & & \\
\hline $\begin{array}{l}\text { 2.6 Aporte de datos que permitan comprender los efectos y resultados potenciales del programa, } \\
\text { e incluso su redefinición, si así fuese necesario. }\end{array}$ & & & & \\
\hline 3. Calidad de los resultados & & & & \\
\hline $\begin{array}{l}\text { 3.1 Diversidad de aprendizajes: en su naturaleza (formal, informal), en su dimensión (conceptual, } \\
\text { procedimental, actitudinal, emocional, social). }\end{array}$ & & & & \\
\hline 3.2 Participación e implicación social & & & & \\
\hline 3.4 Rentabilidad: cultural, social e identitaria. & & & & \\
\hline 3.5 Adquisición de valores hacia el patrimonio establecidos en el diseño & & & & \\
\hline 4. Grado de difusión de los programas y sus resultados & & & & \\
\hline 4.1 Divulgación pública del proyecto realizado (publicación impresa o digital) & & & & \\
\hline 4.2 Publicación de artículos, libros o capítulos de libro en los que se analice el proyecto & & & & \\
\hline
\end{tabular}

\begin{tabular}{|c|c|c|c|}
\hline Dimensiones y estándares & A & \begin{tabular}{|l|l|l} 
B & C \\
\end{tabular} & C $\bar{c}$ \\
\hline E1. Usabilidad & & & \\
\hline E2. Funcionabilidad & & & \\
\hline E3. Aplicabilidad & & & \\
\hline E4. Diversificación de usuarios en función de edades y competencias & & & \\
\hline E5. Consideración de heterogeneidad de grupos & & & \\
\hline
\end{tabular}


Tabla 4. Descripción cuantitativa de la muestra según fases de selección.

\begin{tabular}{|l|c|}
\hline \multicolumn{1}{|c|}{ Fase selección } & Muestra \\
\hline 1‥ Búsqueda y localización & 6.230 \\
\hline 2ㅇ. Inclusión y exclusión & 2.340 \\
\hline 3o. Inventario & 1406 \\
\hline 4ㅇ. Evaluación estándares básica & 135 \\
\hline 5‥ Evaluación estándares extendida & 56 \\
\hline 6‥ Estudio de casos & 6 \\
\hline
\end{tabular}

Fuente: elaboración propia.

Los 56 programas recogidos en este primer análisis estadístico-descriptivo han sido sometidos a la evaluación basada en estándares, habiendo resultado una selección de seis programas que son objeto del estudio de caso sectorial. Para ello, hemos partido de una curva media, mostrando aquellas propuestas que se sitúan en la franja B-C de cumplimiento de los estándares generales, de manera que reúnen gran parte de los estándares de diseño, implementación y resultados generales, y que se sitúan en la franja A en los estándares específicos (véase figura 2).

Una vez sometidos a evaluación basada en estándares, encontramos que solo dos programas se sitúan en el grado de cumplimiento A, cuatro en el B y tres en el $C$, lo que genera una muestra de seis programas, cuya singularidad y grado de calidad nos permiten situarlos como ejemplos, y de los que proponemos un análisis detallado en base a lo que definimos en el siguiente epígrafe como variables estructurantes, para mostrarlos como programas referentes, convirtiéndoles en nuestra muestra sometida a estudio de caso.

\section{Caracterización de la muestra: variables estructurantes en educación patrimonial y TIC}

Todos los programas analizados pivotan sobre una serie de variables estructurantes que se complementan e interrelacionan. Estos conceptos que caracterizan la muestra son organizados en dos cadenas: por un lado, los conceptos básicos principales que son Patrimonio, Educación Patrimonial y TIC y, junto a ellos, pero no de manera subordinada, una segunda cadena de conceptos con capacidad de interrelación, que estructuran el universo de la utilización de las TIC en la educación patrimonial, conformada por Innovación Educativa, Enseñanza-Aprendizaje y Evaluación (véase figura 3).

Así, la concepción de patrimonio que presentan estos programas debería acercarse a la idea del patrimonio como un constructo social (González Monfort, 2007) de carácter holístico (Estepa y Cuenca, 2006), en una definición que asumimos como afectivo-simbólica. Ya Ballart (2001) afirmó que la valoración de los objetos patrimoniales no es inherente a los mismos, sino que se trata de una cualidad añadida por las personas, siendo un concepto relativo, que se añade a una selección de bienes y valores de una cultura concreta y que, por ello, cada forma parte de la propiedad simbólica o real de grupos determinados, lo que en consecuencia incide en la identidad individual y colectiva (Fontal, 2003). González Monfort (2007) describe la idea del patrimonio como un constructo social atribuible a grupos identificables que reconocen, seleccionan y adoptan voluntariamente elementos y manifestaciones, como legado para la comprensión de las raíces, de su presente y en la prefiguración de su futuro, afirmando claramente

Figura 2. Tabla de estándares de un programa tipo B-C general + A específico

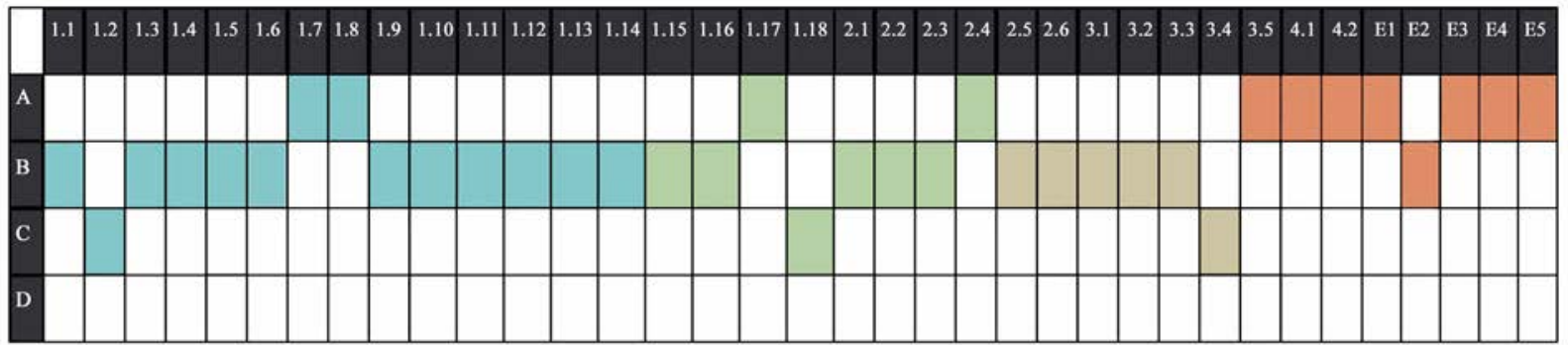

Fuente: elaboración propia. 
Figura 3. Variables estructurantes en educación patrimonial y TIC.

\section{Variables estructurantes en Educación Patrimonial y TICs}

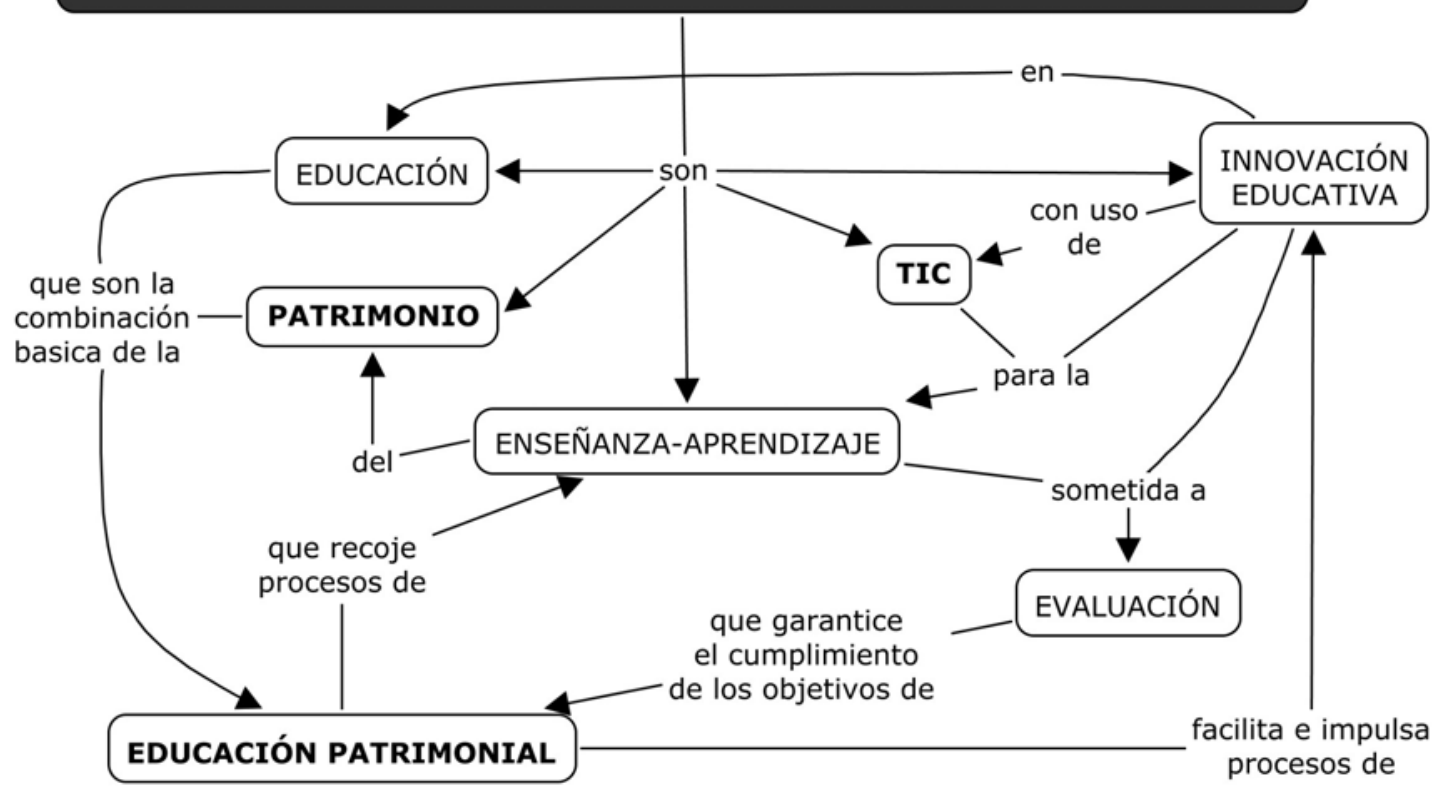

Fuente: elaboración propia.

ese carácter identitario del patrimonio (Kortabitarte, Gillate, Molero y Delgado, 2015).

Sobre esta concepción afectivo-simbólica del patrimonio, en relación a las derivadas educativas de la misma, asumimos como variable estructurante la estrategia de la secuencia significativa de procedimientos para la educación patrimonial de Fontal (2003), por la cual la dimensión afectiva del patrimonio se une de manera indisoluble, y al mismo nivel de significatividad, con el conocimiento conceptual básico, para así garantizar el conocimiento, preservación y transmisión del patrimonio en todas sus dimensiones. Estas ideas en torno al conocimientocompresión-comunicación y al despertar de valores individuales y grupales son el eje conductor y marco de referencia de las actividades educativas con el patrimonio como centro. La secuencia circular o en espiral Conocer para Comprender, para Respetar, para Valorar, para Cuidar, para Disfrutar, para Transmitir para Conocer, recoge de manera gráfica y sencilla los objetivos que debe tener la educación patrimonial (véase figura 4).

Por TIC entendemos todos aquellos recursos que nos ofrece el mundo digital, en un continuo cambio, tanto el hardware fijo o móvil, como el software que hace que estos funcionen, programas y aplicaciones específicas o apps. No obstante, desde el punto de vista de la educación, consideramos que lo relevante es hablar de usos innovadores de la tecnología (Vicent e Ibáñez Etxeberria, 2012).

Dentro de la segunda cadena de conceptos con capacidad de interrelación que nos permiten estructurar el tema, en primer lugar, hablamos de innovación educativa. Durante años, se ha aplicado una ecuación errónea al mundo de la integración de TIC en educación -y también en entornos patrimoniales-, según la cual, cualquier innovación tecnológica se convertía rápidamente en una innovación educativa (Salinas, 2004). En nuestro ámbito, por sus características favorecedoras de experimentación, en los entornos patrimoniales más diversos, se ha hecho un gran número de experimentos de integración de TIC, donde complejas y costosas -o no tanto-, instalaciones tecnológicas se han puesto al servicio del público, con la esperanza final de que el visitante o usuario de esos espacios aprendiera algo. Esa visión del proceso educativo como algo inevitable, ha provocado que, en muchos casos, innovaciones tecnológicas se presentaran automáticamente de manera ilícita como innovaciones educativas, cuando en muchos de los casos, la introducción de esas innovaciones solo ha supuesto un cambio en el medio transmisor del mensaje, pero los procesos transmisivos se han repetido sobre esquemas tradicionales (Ibáñez Etxeberria, Vicent, Asensio, Cuenca y Fontal Merillas, 2014). 
Figura 4. Secuencia significativa de procedimientos para la educación patrimonial.

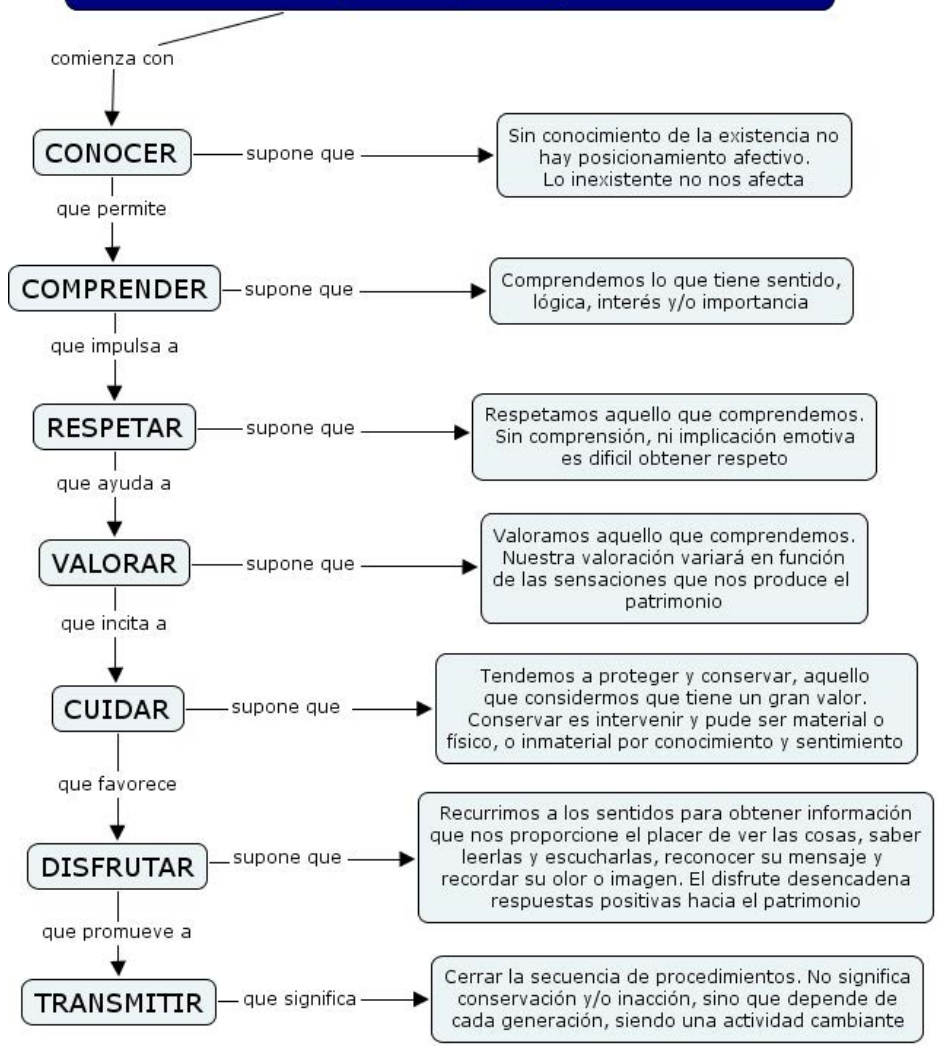

Fuente: Fontal, 2003

Esto se ha podido dar porque un gran número de intervenciones se han realizado al margen de los procesos de enseñanza-aprendizaje que debería buscar toda acción de educación patrimonial, independientemente del entorno formal o informal en que se encuentre el visitante o aprendiz. Así, esto supone un déficit fundamental si entendemos la enseñanzaaprendizaje de cualquier ámbito o concepto como esa vía de doble dirección donde el éxito de los procesos no se mide en el atractivo, innovación o calidad de los medios presentados, sino en la calidad del proceso educativo que queda finalmente reflejado en la conciencia del educando.

Finalmente, y cerrando el círculo del aprendizaje en torno a la educación patrimonial, encontramos la variable evaluación, que estructuralmente -como lo demuestra la bibliografía-, es el eslabón más débil de esta cadena conceptual. Si asumimos la evaluación educativa como una herramienta indiscutible para garantizar la calidad de los procesos educativos y el instrumento que puede posibilitar la mejora continua de esos procesos (Lukas y Santiago, 2004), habremos de convenir que su aplicación debe ser un elemento indispensable que cierre el círculo de la innovación, de manera que podamos reflexionar, y sacar conclusiones, que permitan garantizar que los objetivos educativos se han cumplido y en qué medida, y si no ha sido así, saber por qué, y de qué manera debemos trabajar para subsanar estos déficits.

Así pues, en este escenario deseable de educación patrimonial y TIC, tras el proceso de búsqueda y selección en base a estándares descrito, buscamos proyectos realizados sobre espacios de presentación del patrimonio, que contengan estas variables estructurantes. En su selección, buscamos registros que señalen que, mediante la integración y uso de TIC, se influye de manera positiva en los procesos de enseñanza-aprendizaje ligados a los objetivos de la educación patrimonial. El conocimiento y análisis de estos programas ha de permitir, desde la reflexión sobre la experiencia, una traslación y adecuación a otros escenarios, de manera que se permita participar colectiva- 
mente en la creación de ese conocimiento compartido en torno a los procesos educativos que se dan con los elementos patrimoniales.

Sobre estas premisas, obtenemos los seis proyectos que han conformado el estudio de caso sectorial y que narramos a continuación.

\section{Invisible Maps}

Dentro de la gran oferta de rutas basadas en códigos QR impulsadas por los más diversos colectivos que encontramos en la actualidad en España, una muy interesante es el proyecto Invisible Maps. Surgido en 2011 desde el Museu del Disseny de Barcelona se presenta como "una iniciativa para localizar y hacer visible el patrimonio inmaterial de la ciudad". En opinión de los creadores, "a través del tiempo y los años la ciudad ha cambiado mucho, cada capa nueva transforma y oculta la anterior", por lo que "la participación ciudadana toma un nuevo valor con el objetivo de recuperar los recuerdos ocultos en la memoria de la gente, miles de fragmentos que se recomponen y ubican en la ciudad dejándonos comprender mejor el entorno urbano que nos rodea". Invisible Maps plantea una visión de Barcelona centrada en esta participación, destacando los hechos y lugares que han marcado profundamente las experiencias personales. De esta manera, crea un mapa del patrimonio invisible de la ciudad.

La iniciativa se desarrolla a través de unos talleres en los que muestran al público cómo participar creando sus propios códigos QR para posteriormente transformar sus experiencias personales en contenidos digitales, vinculando el "yo interior" con el exterior de la ciudad. Estos códigos QR ofrecen la oportunidad de interactuar con el territorio y su historia, creando unos contenidos que son accesibles a través de tecnología móvil.

Según los impulsores de esta iniciativa, los beneficios que se obtienen son: 1) conocer la ciudad y crear experiencias colectivas para una mejor comprensión del presente, 2) crear un diálogo entre tecnología y sociedad, 3) promover la participación interactiva ciudadana con componentes sociales y antropológicos, 4) facilitar a los ciudadanos una imagen de la propia ciudad donde viven comprensible y motivadora y 5) crear nuevos escenarios de comunicación, virtuales y reales.

Evaluado externamente, el resultado es desigual. En cuanto a la participación e interés captado, si analizamos la actividad a través de su perfil de twitter, vemos que, durante los catorce meses de vigencia del proyecto, no generaron excesivas interacciones en torno al mismo. Por el contrario, si nos acercamos a la web, los rastros de los posts publicados demuestran un gran interés por la participación en los talleres de formación que, ante la demanda, hubieron de ser realizados varias veces.

En cuanto a los resultados del proyecto referidos al contenido digital, este ha legado una serie de rutas minuciosamente estructuradas y organizadas, que tomando como base fotos, videos y textos escritos, consiguen aflorar los objetivos perseguidos, valorizando esa serie de patrimonios inmateriales personales $y$ colectivos que también se aprecian en la web, y que demuestran que una actividad planteada secuenciadamente acaba teniendo un seguimiento por público que está interesado en participar en esos procesos de patrimonialización en red.

\section{Guía didáctica geolocalizada del Espacio Natural de Quilamas}

Otro proyecto interesante con uso de códigos QR en entornos patrimoniales, es el tour virtual sobre patrimonio geológico del Espacio Natural de Quilamas en Salamanca (Martínez Graña, Goy y Cimarra, 2013). Dicho proyecto crea un tour virtual que consta de diecisiete puntos geológicos o geosite destacables, que se crean en capas que se superponen en Google Earth. Este diseño y utilización de rutas se está popularizando con la integración de los GPS en los smartphones, y hoy en día, disponemos de múltiples apps que nos permiten crear nuestras propias rutas. En este proyecto se crea una ficha para cada punto, y la novedad es que en la misma se introduce una clasificación que nos remite a la apreciación de su valor científico, turístico y educativo (Bruschi y Cendrero, 2005). Este sistema califica cada elemento dentro de los tres ámbitos de referencia en torno a cuatro variables a las que otorga un valor de 1 a 3. Así, los criterios científicos son: abundancia-rarezadiversidad, relevancia en el entorno, utilidad para interpretar procesos, e interés científico y de investigación; los criterios educativos por su parte son: facilidad de comprensión, condiciones de visita, posibilidad de realizar actividades y asociación con otros elementos geológicos y, finalmente, los criterios turísticos son: proximidad a infraestructuras y equipamientos, calidad del entorno, accesibilidad y asociación con otros elementos de interés patrimonial (natural, histórico o cultural).

Con esta idea, las rutas previamente diseñadas pueden ser preparadas desde nuestra casa o institución, pero a su vez, pueden ser insertadas in situ a través de la instalación de códigos QR, con un muy bajo impacto en el entorno. 
Con este tipo de trabajos, estamos ofertando recursos de aprendizaje a la comunidad educativa, transversales o limitados a una única área de conocimiento, para trabajar en el aula, en casa o in situ, que convierten nuestro patrimonio en objeto de aprendizaje. Así, las experiencias de aprendizaje se van extendiendo hacia el aprendizaje a lo largo de toda la vida, el aprendizaje de libre elección y el aprendizaje ubicuo, pero también incluyen las instituciones formales de aprendizaje, centros escolares a los que también se quiere llegar a través de una adecuada implicación del profesorado para poder garantizar una continuidad en los procesos de conservación y comunicación del patrimonio.

\section{Proyecto de trabajo QRcodificación de las calles de Rubí e Itinerario de Viladecavalls a Can Sanahuja}

Un buen trabajo de implicación de la comunidad escolar y de las instituciones locales son los proyectos QRcodificación de las calles de Rubí e Itinerario de Viladecavalls a Can Sanahuja (Silva, 2013). El primero consiste en el compendio de trabajos de diversos centros escolares que trabajaron sobre los nombres de las calles del centro urbano. Esta práctica habitual adquiere otra dimensión cuando toda la información textual y multimedia (imagen, audio y vídeo) se publica en un blog elaborado a tal efecto. En cada calle, se genera un código QR y, en colaboración con el ayuntamiento, se coloca debajo de cada una de las placas identificativas de la calle, para que cualquier ciudadano que disponga de un smartphone acceda a los trabajos realizados por el alumnado. Proyecto gemelo pero en entorno rural, es el Itinerario de paisaje de Can Sanahuja, donde, utilizando el mismo sistema, se puede acceder a los trabajos realizados por el alumnado sobre 25 puntos de diferentes elementos del paisaje: flora, fauna, cultivos, masías y vistas panorámicas que se encuentran en un recorrido por las afueras del pueblo, y que se recogen también en 25 blogs sobre los que se ha generado el correspondiente código QR, accesible desde placas que el ayuntamiento ha integrado en el paisaje.

Un proyecto que da un paso más allá en cuanto a su concepción patrimonial, generación de contenido digital por parte del alumnado y participación social es, dentro del proyecto QRcodificación de las calles de Rubí, el trabajo realizado en torno a la conmemoración del 50 aniversario de la Riada de Rubí (Silva, 2013). Realizado por alumnado de secundaria, consistió en la realización de una ruta de siete puntos a lo largo de la actual riera de Rubí. Sobre cada punto, el alumnado de la ESO de diferentes institutos, realizó una investigación documental y gráfica que concluyó con la creación, sobre cada uno de esos siete puntos, de una pequeña galería fotográfica con imágenes de 1962 o anteriores, imágenes actuales, un texto explicativo y una grabación de audio con el contenido del mismo, así como un pequeño vídeo relatando cómo era aquel lugar hace 50 años. Cada uno de los ficheros de texto, imagen, sonido y vídeo se publicaron en Internet y se «empaquetaron» en siete páginas asociadas a cada uno de los puntos, sobre las que se generó un código $Q R$, y en cada uno de los puntos seleccionados se instalaron paneles informativos que incluían un mapa de la riera con la situación del punto, una imagen del lugar en 1962, un texto y el código QR que enlazaba con el resto de información multimedia trabajada por el alumnado.

\section{App del MARQ de Alicante}

Otra tendencia en educación patrimonial es la creación de apps específicas desde instituciones y museos, donde entendemos por app o aplicación de descarga rápida, un programa destinado a dispositivos móviles (tablets, smartphones), que presenta unas características especiales. Son más pequeñas y específicas y su uso suele limitarse a algo muy concreto, como juegos, herramientas para redes sociales, noticias e información, utilidades para fotos, vídeos o música.

En este panorama expansivo, si a mediados de 2012 tan solo tres grandes museos de arte de España como el Guggenheim, el Picasso y el Reina Sofía contaban con una app (López, 2012), en la actualidad, una visita a los market nos ofrece una gran cantidad de apps entre las que elegir. Una de ellas, es la del MARQ de Alicante que, en versión gratuita, ofrece una app con actividades didácticas relacionadas con los contenidos de las salas para adultos y niños. La utilización de esta aplicación, en su versión para iPod, ha sido evaluada por Romero Cortijo (2013), que ha realizado un estudio con un grupo de 50 escolares divididos en grupo experimental y grupo de control, a los que ha preguntado sobre su percepción de aprendizaje y su satisfacción con la tarea. También ha triangulado la información con entrevistas a los maestros y con tareas de observación.

Los resultados le permiten concluir que el uso de aplicaciones móviles como recurso educativo para la difusión del patrimonio arqueológico, en contraposición con la ausencia de materiales didácticos de apoyo o el empleo de recursos tradicionales, posibilita una mayor y mejor construcción de aprendizajes significativos por parte de los visitantes escolares en la medida en que se producen las condiciones idóneas 
para el desarrollo de este tipo de aprendizajes. Con respecto a la estructura de la $a p p$, que presenta una serie de actividades educativas con respuesta de elección múltiple, concluye que la voluntad de dotar a la aplicación de un sistema de autocorrección produce que en ocasiones se roce un enfoque conductista basado en procesos automatizados de copia, en lugar de mecanismos de reflexión mental.

\section{Blog People and Heritage}

Este blog consta de una galería de imágenes que tratan con personas y la interacción con sus patrimonios de referencia. Se pretende mostrar algunos elementos significativos de la arquitectura, el espacio urbano, el arte público y otras expresiones culturales. Estos elementos se han fotografiado y editado como un cartel por los alumnos del grado de educación primaria del Colegio Cardenal Cisneros de la Universidad de Alcalá, y los de la Facultad de Educación de la Universidad de Laponia de Rovaniemi en Finlandia.

Un tema común en cada cartel es la inclusión de una parte del cuerpo humano, con el objetivo de transmitir cómo la gente común puede interrelacionar con el patrimonio, con el propósito de vincularlos a los propios referentes culturales.

Al final, los estudiantes fueron invitados a subir sus trabajos a la página web con el fin de que fueran compartidos y apreciados públicamente. El formato de blog ofrece la posibilidad de admirar todos los carteles juntos en una galería única, y también dejar comentarios sobre cualquiera de ellos. De esta manera, se fomentan nuevas oportunidades para que el patrimonio resulte más cercano a la gente.

\section{El cibermuseo VIRGO}

El VIRtual Generator and Organizer (VIRGO) ha sido creado en el marco del proyecto Aplicación didáctica de la cibermuseografía de la Fundación Aragón I+D. Esta herramienta está estructurada en tres ambientes separados: un repositorio de piezas arqueológicas procedentes de la ciudad romana de Bílbilis en modelos digitales visionados a 360 o grados, una sala virtual que simula un museo para crear exposiciones en $3 D$ y que constituye el espacio de actividad del usuario; y el museo virtual en 3D para visitar las exposiciones creadas. El usuario selecciona del repositorio las piezas que van a conformar su exposición; posteriormente en la sala virtual elije, sitúa y da color a los elementos expositivos, ubica en ellos las piezas seleccionadas, redacta las cartelas y decide si incluir archivos que hagan la función de paneles explicativos o enlaces a videos del canal you tube del museo de Calatayud que sirvan como audiovisuales asociados a la exposición.

El usuario adquiere, por tanto, un rol activo en la construcción de conocimiento a través de la reflexión sobre el propio discurso expositivo que quiere realizar mediante los objetos arqueológicos seleccionados de la colección. Supone un ejemplo de interactividad constructiva aplicada a la educación patrimonial propia de la web 2.0 que cuenta con escasos paralelos a nivel mundial, donde solo Clark Remix ${ }^{\mathrm{TM}}$-uCurate podría considerarse similar pese a las diferencias contextuales y propiamente metodológicas.

\section{DISCUSIÓN Y CONCLUSIONES: TENDENCIAS Y PERSPECTIVAS DE FUTURO}

\section{Tecnología móvil en espacios de presentación del patrimonio y museos en España: realidad aumentada, códigos QR y apps}

Podemos ver que la implantación de propuestas de innovación educativa mediadas por tecnología en entornos de presentación del patrimonio y museos se encamina hacia el desarrollo de actividades de educación patrimonial en las que las tecnologías móviles y el aprendizaje ubicuo van a ser los ejes básicos de desarrollo. A ello ayuda la imparable extensión de la tecnología móvil (smartphones y conexiones wi-fi y 3G-4G), que está permitiendo el desarrollo de aplicaciones sencillas y accesibles con actividades para entornos patrimoniales.

Uno de los recursos con más recorrido va a ser la realidad aumentada (AR), entendida como aquella tecnología que permite al usuario ver en todo momento el mundo real, con superposición de objetos virtuales, coexistiendo en el mismo espacio visual (Azuma, 1997). Sus características principales son combinar lo real y lo virtual en un entorno real, poseer interactividad en tiempo real y ser un registro en 3D (Azuma et al., 2001), creando una realidad mixta y permitiendo disponer de mucha mayor información. La principal diferencia con la realidad virtual (VR) es que no sustituye la realidad física, sino que superpone la información digital en tiempo real, al mundo real (Basogain, Olabe, Espinosa, Rouèche y Olabe, 2007), permitiendo al usuario interactuar, además de ser más barata y accesible.

Otra actividad en escena son los códigos QR, una evolución de los tradicionales códigos de barras, a los que accedemos con cualquier dispositivo móvil con cámara y una aplicación o app de lectura adecuada (Silva, 2013), cuya evolución futura podría llevarnos hacia los iBeacons. En la actualidad, debido a las ven- 
tajas que ofrece este sistema de presentación y distribución de la información, hemos vivido una eclosión de su presencia en el ámbito educativo en escenarios patrimoniales. Su accesibilidad y bajo costo, pequeño impacto visual, la posibilidad de fácil de actualización $y$, hasta hace bien poco, su carácter modernizador y su reversibilidad, han hecho de esta tecnología uno de los campos activos en señalización cultural ligada al patrimonio, aunque hoy en día se esté encontrando en un franco retroceso. Este es el camino que previsiblemente seguirá la evolución de los iBeacons, pero por ahora su implementación se halla en fase inicial y solo se lo pueden permitir grandes equipamientos.

Por ahora, la facilidad que tenemos para editar información digital y lo sencillo de crear los códigos $Q R$, está ofreciendo la posibilidad de que la comunidad participe en la creación de sus propias rutas patrimoniales entendidas desde ese concepto moderno de patrimonio, en el que el grupo decide lo que es importante en su identidad. Su utilización y su devenir de uso nos dirá si esa ruta profundiza en el proceso patrimonializador que representa el modelo de pasos de Fontal (2003).

Finalmente, el desarrollo de las apps en educación patrimonial, camina entre un nuevo furor y las limitaciones de su uso en condiciones que mejoren el aprendizaje. Todavía es pronto para sacar más conclusiones de las escasas evaluaciones realizadas, pero creemos que mientras este recurso lidera claramente el ámbito de la inclusión, a la vez se halla en una encrucijada de identidad educativa de la que habremos de ver su desarrollo futuro en base a unas potencialidades evidentes.

\section{Espacios de interactividad creativa y participación social}

El afianzamiento de la web 2.0, definida como espacio de interacción, participación y creación social por parte de los usuarios, posibilita actividades de $e$ learning aplicadas a la educación patrimonial desde un planteamiento constructivista. La discusión y participación en blogs y redes sociales no siempre refleja un uso multidireccional de la información y también son todavía escasos los ejemplos de dinamización de redes sociales con finalidad clara de educación patrimonial y de creación de comunidades de aprendizaje on line. Cabe destacar diferentes iniciativas globales de twitter para dinamizar la red social con contenidos que podemos relacionar con la educación patrimonial, como \#Cultura 18 o \#MuseumWeek.

Asimismo, la presencia de proyectos españoles vinculados a la educación patrimonial en mundos virtuales, como second life, es muy escasa en comparación con las actividades de los países anglosajones (Vicent, Rivero y Feliu, 2015) y limitada a la reconstrucción de algún resto patrimonial. No obstante, en la actualidad asistimos a una reestructuración de la oferta en fun-

Figura 5. Características principales que han favorecido la implantación de códigos QR en espacios patrimoniales.

\section{Códigos QR en Patrimonio}

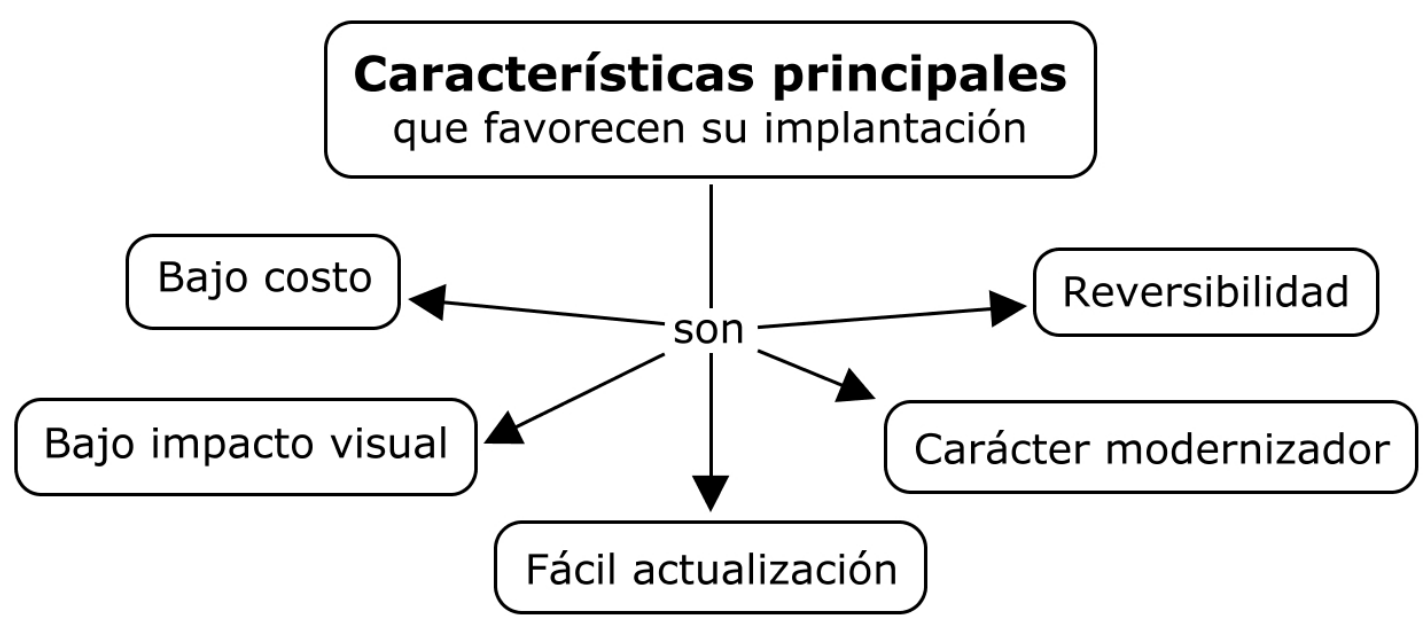

Fuente: elaboración propia. 
ción de su adaptabilidad a dispositivos móviles y su adecuación a diferentes perfiles de público, por lo que podemos calificar el momento como de transición.

Finalmente, la potencialidad de la web 2.0 para compartir información y crear recursos de manera colaborativa se ha plasmado en algunas iniciativas de recopilación de documentos para que pasen a formar parte del archivo digital del museo. Así, el proyecto Fotoscopia del Museo de la vida rural de L'Espluga de Francolí, lanzado en 2011, puede considerarse un ejemplo pionero al respecto. La creación de exposiciones virtuales on line por parte de los usuarios constituye otra vía de participación social de alta potencialidad educativa. Junto a iniciativas experimentales como VIRGO, no hay que dejar a un lado herramientas como la Open Gallery de Google que es previsible incorporen los museos incluidos en el Google Art Project, unos 30 de ellos españoles. Pero en cualquier caso de momento la utilización de la web 2.0 como herramienta para la educación patrimonial parece escasa respecto a su elevada potencialidad para desarrollar propuestas de enseñanza-aprendizaje constructivas y significativas (Martín Cáceres y Cuenca López, 2015).

\section{La necesidad de la evaluación en educación patrimo- nial y TIC}

No podemos terminar sin hablar de evaluación. Los escenarios patrimoniales son unos excelentes entornos para la implementación experimental de tecnologías emergentes. Sus posibilidades, su capacidad de atracción a públicos interesados, su valor positivo y su fácil venta social, entre otros, han hecho que, en los años anteriores a la actual crisis económica, hayan sido múltiples las iniciativas con base de tecnología digital en nuestros espacios patrimoniales (Asensio y Asenjo, 2011; Vicent e Ibáñez Etxeberria, 2012) pero en contraposición resultan muy escasos los ejemplos de evaluación científica de los resultados obtenidos.

Uno de los primeros programas de los que tenemos constancia por la publicación de los resultados de su evaluación es el del programa de VR de caserío Igartubeiti en Gipuzkoa, el cual, en época temprana realizó una interesante, por precoz, evaluación educativa (Akordagoitia Murua, 2004).

Un segundo proyecto evaluado de integración de la tecnología, en este caso móvil, en escenarios de presentación del patrimonio es el caso del Museo de Historia y Arte de Zarautz (Vicent, 2013). Este proyecto educativo se diseñó en base al triángulo aprendizaje informal-espacios de presentación del patrimoniomobile learning, con utilización de dispositivos móvi- les tipo PDA y GPS (Ibáñez Etxeberria, Jiménez de Aberasturi, Correa Gorospe y Noarbe de la Casa, 2005). En un primer programa se evaluaron los parámetros de portabilidad, accesibilidad, uso e impacto (Correa, Ibáñez Etxeberria y Jiménez, 2006), siendo mayoría los que declararon haber aprendido; sin embargo, se constató que existían serias dificultades para concretar el tipo de aprendizajes que se habían logrado. También se pudo apreciar la gran motivación que supone para los alumnos el realizar un trabajo de campo sobre el terreno y con este tipo de tecnologías. Una nueva versión del programa fue evaluada buscando el aprendizaje producido (Ibáñez Etxeberria, Vicent y Asensio, 2012, Ibañez Etxeberria et al., 2014). Los resultados confirmaron la alta satisfacción y la percepción de los dispositivos móviles como herramientas que mejoran las condiciones de aprendizaje y hacen que este sea más sencillo y agradable, así como que los contenidos trabajados a través de los mismos son bien adquiridos.

En el proyecto del cibermuseo VIRGO la evaluación incluyó además entre sus dimensiones la carga de trabajo que conlleva la utilización de tecnologías complejas. Para ello se recurrió a un instrumento ya verificado: el índice de carga de tarea NASA-TLX (Hart y Staveland, 1988), que está diseñado para medir aspectos como la exigencia mental, la exigencia física, la exigencia temporal, esfuerzo, rendimiento y nivel de satisfacción. Su aplicación proporcionó como resultados una carga de trabajo global de entre el $66 \%$ y el $36 \%$ en función de los usuarios, si bien el nivel de frustración fue bajo mientras que el de rendimiento resultó alto. La información cualitativa proporcionada por los participantes en la evaluación explicó que esto se debía a que, una vez dominada la herramienta, su manejo resultaba sencillo y se puede aplicar a muchas actividades diferentes y en distintas etapas educativas por lo que finalmente su uso era muy satisfactorio (Rivero y Flores-Hole, 2014). Otra dimensión escasamente analizada es el proceso de interacción en los espacios web 2.0 de difusión patrimonial, que constituye una línea de trabajo emergente.

Recientemente, nuevos proyectos relacionados con el uso de la tecnología móvil en espacios patrimoniales en España han publicado sus resultados de evaluación como Movilizate (García Andrés y Andrés López, 2014), y Arqueólogos del siglo XXI (González Sanz, 2014), pero ello no oculta que este ámbito se ha trabajado poco, y que supone uno de los ámbitos de la educación patrimonial y TIC que necesita una urgente mejora. 


\section{AGRADECIMIENTOS}

Este artículo recoge resultados financiados desde tres proyectos financiados por el Ministerio de Economía y Competitividad en el marco del programa de investigación fundamental no orientada: Observatorio de Educación Patrimonial en España. Análisis integral del estado de la educación patrimonial en España (EDU2012-37212), Educación Patrimonial en España: Consolidación, evaluación de programas e internacio- nalización del observatorio de educación patrimonial en España (OEPE) (EDU2009-09679) y Evaluación cualitativa de la acción cultural de yacimientos romanos con web 2.0 (CIVITAS) (HAR2013-48456-C3-3-P), así como desde del proyecto Apps, redes sociales, dispositivos móviles y ubiquitous learning en Educación Patrimonial (EHU15/16), de la Convocatoria de Ayudas a la investigación EHU-UPV 2015.

\section{NOTAS}

1. Ley Orgánica General del Sistema Educativo, de 3 de octubre de 1990 (Boletín Oficial del Estado de 4 de octubre de 1990).

2. Ley Orgánica de Educación, de 3 de mayo de 2006 (Boletín Oficial del Estado de 4 de mayo de 2006).

\section{BIBLIOGRAFÍA}

Akordagoitia Murua, M. (2004). El Caserío Igartubeiti: análisis de la musealización de un museo desde su vertiente presencial y virtual. Iber. Didáctica de las Ciencias Sociales, Geografía e Historia, 10 (39), pp. 77-83.

Asensio, M. y Asenjo, E. (eds.) (2011). Lazos de luz azul: Museos y tecnologías 1, 2 y 3.0. Barcelona: Universitat Oberta de Catalunya.

Azuma R. (1997). A Survey of Augmented Reality. Presence: Teleoperators and Virtual Environments, 6 (4), pp. 355-385. https:// doi.org/10.1162/pres.1997.6.4.355

Azuma, R., Baillot, Y., Behringer, R., Feiner, S., Julier, S., y Macintyre, B. (2001). Recent Advances in Augmented Reality. IEEE Computer Graphics and Applications, 21 (6), pp. 34-47. https://doi. org/10.1109/38.963459

Ballart, J. (2001). El patrimonio histórico y arqueológico: valor y uso. Barcelona: Ariel.

Basogain, X., Olabe, M., Espinosa, K., Rouèche, C. y Olabe, J. C. (2007). Realidad Aumentada en la Educación: una tecnología emergente. [En línea]. Disponible en: http://files.mediaticos. webnode.es/200000016-a645ea73b3/ realidad\%20A..pdf

Bruschi, V. M. y Cendrero, A. (2005). Geosite evaluation: can we measure intangi-
3. Ley Orgánica para la Mejora de la Calidad Educativa de 9 de diciembre de 2013 (Boletín Oficial del Estado de 10 de diciembre de 2013).

4. Datos obtenidos con fecha 9 de enero de 2015. ble values? II Quaternario. Italian Journal of Quaternary Sciences, 18 (1), pp. 291-306.

Correa, J. M., Ibáñez Etxeberria, A. y Jiménez, E. (2006). Lurquest: Aplicación de tecnología «m-learning» al aprendizaje del patrimonio. Iber. Didactica de las Ciencias Sociales, 50, pp. 109-123.

Cuenca, J. M. y López-Cruz, I. (2014). La enseñanza del patrimonio en los libros de texto de Ciencias Sociales, Geografía e Historia. Cultura y Educación / Culture and Education, 26 (1), pp. 1-43.

Domingo, M., Fontal, O., Cirujano, C. y Ballesteros, P. (2013). Plan Nacional de Educación y Patrimonio. Madrid: Ministerio de Educación, Cultura y Deporte.

Estepa, J. y Cuenca, J. M. (2006). La mirada de los maestros, profesores y gestores del patrimonio. Investigación sobre concepciones acerca del patrimonio y su didáctica. En: Calaf, R. y Fontal, O. (eds.). Miradas al patrimonio. Oviedo: Trea, pp. 51-71.

Fontal, O. (2003). La educación patrimonial: teoría y práctica en el aula, el museo e Internet. Gijón: Trea.

Fontal, O. (2013). Informe sobre el Análisis del tratamiento del Patrimonio Cultural en la legislación educativa vigente. Madrid: Instituto del Patrimonio Cultural de España.
Fontal, O. (2016). The Spanish Heritage Education Observatory / El Observatorio de Educación Patrimonial en España. Cultura y Educación / Culture and Education. 28 (1), pp. 254-266. https://doi. org/10.1080/11356405.2015.1110374

Fontal Merillas, O. (2016). El patrimonio a través de la educación artística en la etapa de primaria. Arte, Individuo y Sociedad, 28 (1), pp. 105-120. https:// doi.org/10.5209/rev_ARIS.2016.v28. $\mathrm{n} 1.47683$

Fontal Merillas, O. e Ibáñez Etxeberria, A. (2015). Estrategias e instrumentos para la educación patrimonial en España, Educatio Siglo XXI, 33 (1), pp. 15-32.

García Andrés, J. y Andrés Lopez, G. (2014). "Burgos de puerta a puerta", una investigación sobre patrimonio monumental y documental mediante realidad aumentada. Ventajas y limitaciones. En: Fontal Merillas, O., Ibáñez Etxeberria, A. y Martín Sánchez, L. (coords.) Reflexionar desde las experiencias. Una visión complementaria entre España, Francia y Brasil. Actas del II Congreso Internacional de Educación Patrimonial. Madrid: Instituto de Patrimonio Cultural de España / Observatorio de Educación Patrimonial en España, pp. 583-598.

González Sanz, M. (2014). Arqueólogos del siglo XXI: apropiarse de la ciudad y del 
patrimonio mediante mobilelearning, realidad aumentada y geolocalización. En: Fontal Merillas, O., Ibáñez Etxeberria, A. y Martín Sánchez, L. (coords.) Reflexionar desde las experiencias. Una visión complementaria entre España, Francia y Brasil. Actas del II Congreso Internacional de Educación Patrimonial. Madrid: Instituto de Patrimonio Cultural de España / Observatorio de Educación Patrimonial en España, pp. 615-626.

González Monfort, N. (2007). L'ús didàctic $i$ el valor educatiu del patrimoni cultural. [Tesis doctoral inédita]. Universidad Autónoma de Barcelona: Barcelona. Disponible en: http://hdl.handle. net/10803/4673

Hart, S. y Staveland, L. (1988). Development of NASA-TLX (Task Load index): Results of empirical and theoretical research. En: Hancock, P. A. y Meshkati, N. (eds.). Human Mental Workload. Amsterdam: North Holland Press, pp. 239-250. https://doi. org/10.1016/S0166-4115(08)62386-9

Ibáñez Etxeberria, A., Jiménez de Aberasturi, E., Correa Gorospe, J. M. y Noarbe de la Casa, R. (2005). Aprendizaje del patrimonio: Una experiencia de integración del m-learning en el Museo de Arte e Historia de Zarautz. Comunicación y Pedagogía, 203, pp. 36-39.

Ibáñez Etxeberria, A., Vicent, N. y Asensio, M. (2012). Aprendizaje informal, patrimonio y dispositivos móviles. Evaluación de una experiencia en educación secundaria. Didáctica de las Ciencias Experimentales y Sociales, 26, pp. 3-18.

Ibáñez Etxeberria, A., Vicent, N., Asensio, M., Cuenca, J. M. y Fontal Merillas, O. (2014). Learning in archaeological sites with mo- bile devices. Munibe Antropologia - Arkeologia, 65, pp. 313-321. https://doi. org/10.21630/maa.2014.65.18

Kortabitarte, A., Gillate, I., Molero, B. y Delgado, A. (2015). Patrimonio, paisaje e identidad: un acercamiento desde la Educación Primaria en el País Vasco. Clío. History and History Teaching, 41, 7.

Lopez, V. (2012). Museos de arte, tecnologías móviles y educación: ¿hacia una nueva manera de interpretar el arte? En: Fontal, O., Ballesteros, P. y Domingo, M. (coords.) I Congreso Internacional de Educación Patrimonial. Mirando a Europa: estado de la cuestión y perspectivas de futuro. Ponencias. Madrid: Ministerio de Educación, Cultura y Deporte, pp. 257-264. Disponible en: http://docs. wixstatic.com/ugd/79b507_7a8daeec5 e04455f8a7f9340020ee676.pdf

Lukas, J. F. y Santiago, K. (2004). Evaluación educativa. Madrid: Alianza.

Martín Cáceres, J. M., y Cuenca López, J. M. (2015). Educomunicación del patrimonio. Educatio Siglo XXI, 33 (1), 33-54. https://doi.org/10.6018/j/222491

Martínez-Graña, A. M., Goy, J. L. y Cimarra, C. A. (2013). A virtual tour of geological heritage: Valourising geodiversity using Google Earth and QR code. Computers \& Geosciences, 61, pp. 83-93. https:// doi.org/10.1016/j.cageo.2013.07.020

Miguel, M. de (2000). La evaluación de programas sociales. Fundamentos y enfoques teóricos. Revista de Investigación Educativa, 18 (2), pp. 289-317.

Pelegrín Campo, J. (2015). La enseñanza de la historia en educación primaria en el marco de la LOMCE. Iber. Didáctica de las ciencias sociales, geografía e historia, 79, pp. 41-48.

Rivero, P. y Flores-Hole, H. (2014). Social Science Teachers' perspective, purposes and benefits of the Cybermuseum VIRGO 1.1. as a cognitive tool for learning history. GSTF International Journal on Education, 2 (1), pp. 26-30.

Romero Cortijo, I. (2013). Aprendizaje significativo mediante las TIC en entornos patrimoniales. Estudio de la aplicación "MARQ" desde la perspectiva de la educación patrimonial en el marco de la Ciudad Educadora. [Trabajo de fin de máster inédito]. Universidad de Murcia: Murcia. Disponible en https://digitum.um.es/ xmlui/bitstream/10201/35950/1/TFM isabel.r.c.pdf

Salinas, J. (2004). Innovación docente y uso de las TIC en la enseñanza universitaria. RUSC. Revista Universidad y Sociedad del Conocimiento, 1 (1), pp. 1-16.

Silva, J. M. (2013). La realidad aumentada dentro y fuera del aula. Aula de secundaria, 4, pp. 19-23.

Vicent, N. (2013). Evaluación de un programa de educación patrimonial basado en tecnología móvil. [Tesis doctoral inédita]. Universidad Autónoma de Madrid: Madrid.

Vicent, N. e Ibáñez Etxeberria, A. (2012). El uso de las nuevas tecnologías y el patrimonio en el ámbito escolar. Aula de Innovación Educativa, 208, pp. 22-27.

Vicent, M., Rivero, P. y Feliu, M. (2015). Arqueología y tecnologías digitales en Educación Patrimonial, Educatio. Siglo XXI, 33 (1), pp. 83-102. https://doi. $\operatorname{org} / 10.6018 / \mathrm{j} / 222511$ 